\title{
Sympatry and resource partitioning between the largest krill consumers around the Antarctic Peninsula
}

\author{
Ari S. Friedlaender ${ }^{1,2, *}$, Trevor Joyce ${ }^{2}$, David W. Johnston ${ }^{3}$, Andrew J. Read ${ }^{3}$, \\ Douglas P. Nowacek ${ }^{3,4}$, Jeremy A. Goldbogen ${ }^{5}$, Nick Gales ${ }^{6}$, John W. Durban ${ }^{2}$ \\ ${ }^{1}$ Institute for Marine Sciences, University of California Santa Cruz, 115 McAllister Way, Santa Cruz, CA 95060, USA \\ ${ }^{2}$ Marine Mammal Institute, Oregon State University, 2030 Marine Science Drive, Newport, OR 97365, USA \\ ${ }^{3}$ Division of Marine Science and Conservation, Nicholas School of the Environment, Duke University Marine Laboratory, \\ 135 Duke Marine Lab Road, Beaufort, NC 28516, USA \\ ${ }^{4}$ Pratt School of Engineering, Duke University, Durham, NC 27708, USA \\ ${ }^{5}$ Hopkins Marine Station, Stanford University, 120 Oceanview Boulevard, Pacific Grove, CA 93950, USA \\ ${ }^{6}$ Australian Antarctic Division, 203 Channel Highway, Kingston, Tasmania 7050, Australia
}

\begin{abstract}
Understanding how closely related, sympatric species distribute themselves relative to their environment is critical to understanding ecosystem structure and function and predicting effects of environmental variation. The Antarctic Peninsula supports high densities of krill and krill consumers; however, the region is warming rapidly, with unknown consequences. Humpback whales Megaptera novaeangliae and Antarctic minke whales Balaenoptera bonaerensis are the largest krill consumers here, yet key data gaps remain about their distribution, behavior, and interactions and how these will be impacted by changing conditions. Using satellite telemetry and novel spatial pointprocess modeling techniques, we quantified habitat use of each species relative to dynamic environmental variables and determined overlap in core habitat areas during summer months when sea ice is at a minimum. We found that humpback whales ranged broadly over continental shelf waters, utilizing nearshore bays, while minke whales restricted their movements to sheltered bays and areas where ice is present. This presents a scenario where minke whale core habitat overlaps substantially with the broader home ranges of humpback whales. While there is no indication that prey is limiting in this ecosystem, increased overlap between these species may arise as climate-driven changes that affect the extent, timing, and duration of seasonal sea ice decrease the amount of preferred foraging habitat for minke whales while concurrently increasing it
\end{abstract}

${ }^{*}$ Corresponding author: ari.friedlaender@ucsc.edu

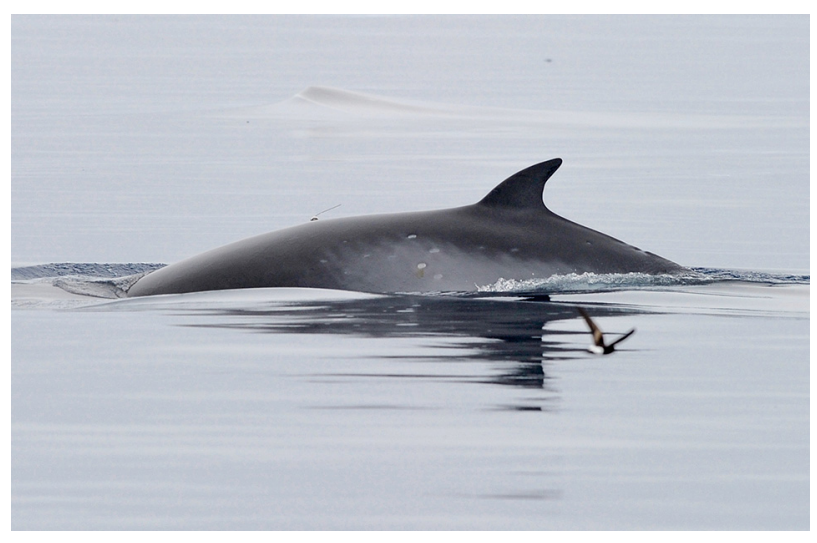

Antarctic minke whale with satellite tag, Wilhelmina Bay, Antarctic Peninsula. Photo collected during NMFS, ACA, and IACUC permitted research.

Photo: Ari S. Friedlaender

for humpback whales. Our results provide the first quantitative assessment of behaviorally based habitat use and sympatry between these 2 krill consumers and offers insight into the potential effects of a rapidly changing environment on the structure and function of a polar ecosystem.

KEY WORDS: Antarctic whales · Humpback whale · Megaptera novaeangliae. Antarctic minke whale · Balaenoptera bonaerensis - Distribution · Satellite telemetry · Animal-movement models · Sympatry

() The authors 2021. Open Access under Creative Commons by Attribution Licence. Use, distribution and reproduction are unrestricted. Authors and original publication must be credited. 


\section{INTRODUCTION}

Closely related species tend to have high diet overlap and similar foraging strategies. In order for such species to co-occur in sympatry and avoid competition, they must partition resources and/or habitats (Hutchinson 1959) via mechanisms such as differential responses to predation risk or habitat use gradients (Schoener 1974). Studies of resource partitioning among related species that forage on individual prey items show that smaller animals typically forage on smaller prey (e.g. Dixon 2007), whereas studies on grazers, which feed on non-mobile vegetation, show that metabolic demands, rather than body size alone, may affect resource selection and habitat use (e.g. Arsenault \& Owen-Smith 2008).

Despite the fact that marine habitats comprise a majority of the Earth's surface, it remains unclear how most sympatric marine predators partition resources to avoid competition (Milne 1961, Clapham \& Brownell 1996). This is mainly due to logistical and economic constraints in conducting field studies in the majority of ocean environments. However, this work is important because the structure and function of marine ecosystems differ in many ways from terrestrial ecosystems, and comparative studies may offer fundamental insights into ecological relationships among species that span these domains (Menge et al. 2009). In marine ecosystems, the presence and abundance of lower trophic level prey available for predators is directly affected by environmental conditions, including sunlight and nutrients. In polar regions, seasonal melting of sea ice helps to stratify the water column, promoting high levels of primary and secondary productivity during summer months when sunlight is increased. Therefore, understanding the habitat use and needs of endemic species is important when considering the impact that broadscale changes in environmental conditions have on habitat quality and quantity, prey availability, and how these may lead to changes in species composition and ecosystem function.

One group of animals that provides a tractable research model for ecosystem function are baleen whales (Mysticeti). These animals exhibit a unique combination of extreme body size, high overall energetic demands, and low mass-specific metabolic rates. Baleen whales have evolved a bulk filter-feeding strategy to take advantage of seasonally abundant yet heterogeneously distributed prey resources (Goldbogen et al. 2017). Baleen as an adaptation and bulk-filter feeding as a strategy appear to have evolved in the Southern Ocean, coincident with the development of the Antarctic Circumpolar Current and coastal upwelling processes in the Oligocene that promote extensive annual primary and secondary marine productivity around the Antarctic continent (Slater et al. 2017, Bianucci et al. 2019). The resultant prey base of euphausiid krill aggregates in dense but ephemeral patches of sufficient biomass to support a diverse assemblage of upper trophic level predators in the region, including whales, seals, penguins, flying seabirds, and finfish (e.g. Trathan \& Hill 2016).

In the Southern Ocean, humpback whales Megaptera novaeangliae and Antarctic minke whales Balaenoptera bonaerensis (AMWs) feed primarily on Antarctic krill Euphausia superba and are 2 of the most abundant baleen whale species inhabiting Antarctic waters (Bejder et al. 2016, Perrin et al. 2018). Recent estimates of AMW abundance are around 500000 individuals, whereas nearly all populations of humpbacks that have been measured recently are close to recovering (or have recovered) from commercial whaling that decimated a population that likely numbered around 130000 (Bejder et al. 2016, Perrin et al. 2018). Specifically in the nearshore waters around the Antarctic Peninsula, humpbacks and AMWs are generally the only baleen whale species encountered (e.g. Friedlaender et al. 2006).

Humpbacks are medium-sized baleen whales averaging $\sim 15 \mathrm{~m}$ in length, whereas AMWs are among the smallest baleen whales, averaging $\sim 8 \mathrm{~m}$ in length. Both species are rorqual whales, which are characterized by a unique suite of morphological adaptations for high-speed engulfment filter-feeding on small-bodied prey. Among rorqual whales, engulfment capacity scales allometrically with body size, allowing for greater foraging efficiency in larger whales that leads to higher mass-specific energetic costs for feeding (Potvin et al. 2012, Kahane-Rapport \& Goldbogen 2018). Thus, larger whales must target higher-density and larger-size prey patches to maximize energetic gains. Because lunge feeding is such an energetically costly feeding strategy, baleen whales are limited in the number of feeding events they can perform on a given dive, and this number scales inversely with body size (AcevedoGutiérrez et al. 2002, Goldbogen et al. 2012).

Humpback whales are seasonally present around the Antarctic Peninsula, spending summer months feeding before migrating in winter to low-latitude breeding grounds thousands of kilometers away (Rasmussen et al. 2007). They generally inhabit continental shelf waters, associating primarily with areas 
of high krill abundance and secondarily with physical features that aggregate prey (Murase et al. 2002, Friedlaender et al. 2006, Santora et al. 2014, Curtice et al. 2015). Conversely, AMWs are present yearround in the Antarctic, although some portion of the population migrates to tropical waters in winter (e.g. Lee et al. 2017). AMWs are most closely associated with sea ice that accretes each winter, and are only secondarily associated with areas of higher prey availability (Friedlaender et al. 2006, Williams et al. 2014). It is thought that AMWs associate with sea ice because their small body size allows them to maneuver in this dynamic environment better than other whales and they are therefore able to exploit krill that may not be available to other krill predators. Furthermore, sea ice is thought to provide some level of protection from killer whales that are known to feed on AMWs in this region (Fearnbach et al. 2019).

Current knowledge of these habitat associations and sympatry among AMWs and humpback whales comes largely from studies made during autumn when sea ice is beginning to form, and/or were based on observations made at sea during surveys rather than from studies of movement patterns and behavior of individuals (Friedlaender et al. 2006, 2009, 2011, Bombosch et al. 2014, Herr et al. 2016). As a result, that work may not fully represent the habitat used by each species, as it does not consider choices that individual animals make over time. The Antarctic Peninsula is also warming more rapidly than nearly any other region on the planet, resulting in decreased sea ice extent and persistence in this region (e.g. Vaughan et al. 2003, Stammerjohn et al. 2012, Meredith et al. 2017). In summer months, nearly all sea ice is absent on the western side of the Antarctic Peninsula, and therefore a major habitat feature for AMWs is no longer available during this time. An important impact of this decrease in sea ice is a likely decline in krill stocks regionally that could eventually affect availability for predators (Atkinson et al. 2019).

The goals of this study were to (1) determine the degree of spatial overlap between humpback and AMWs around the Antarctic Peninsula, (2) evaluate the ecological relationships between these 2 closely related predators, and (3) provide insights as to how rapidly-changing conditions may affect the habitat use and availability of each species. To achieve this, we conducted a novel telemetry-based study, generating concurrent tracking data for both species, used spatial point process modeling of animal movement, and related this to environmental features. Based on previous work, we expected that individually tagged humpback whales range broadly and use a combination of oceanographic and physical features that likely aggregate krill, whereas AMWs will associate primarily with habitat features that decrease predation risk from killer whales while still providing for proximity to areas with suitable prey resources. If environmental conditions (e.g. sea ice loss and krill abundance) continue to change, we expect that the amount of preferred habitat for AMWs during summer months will diminish, and that those areas that do remain will lead to increased sympatry (and potential competition) between these 2 species.

\section{MATERIALS AND METHODS}

\subsection{Study area}

Field work was conducted in the coastal bays associated with the Gerlache and Bransfield Straits on the western side of the Antarctic Peninsula. We constrained our environmental covariate areas to include continental shelf and nearshore waters from the northern tip of the Antarctic Peninsula to south of Crystal Sound (Fig. 1).

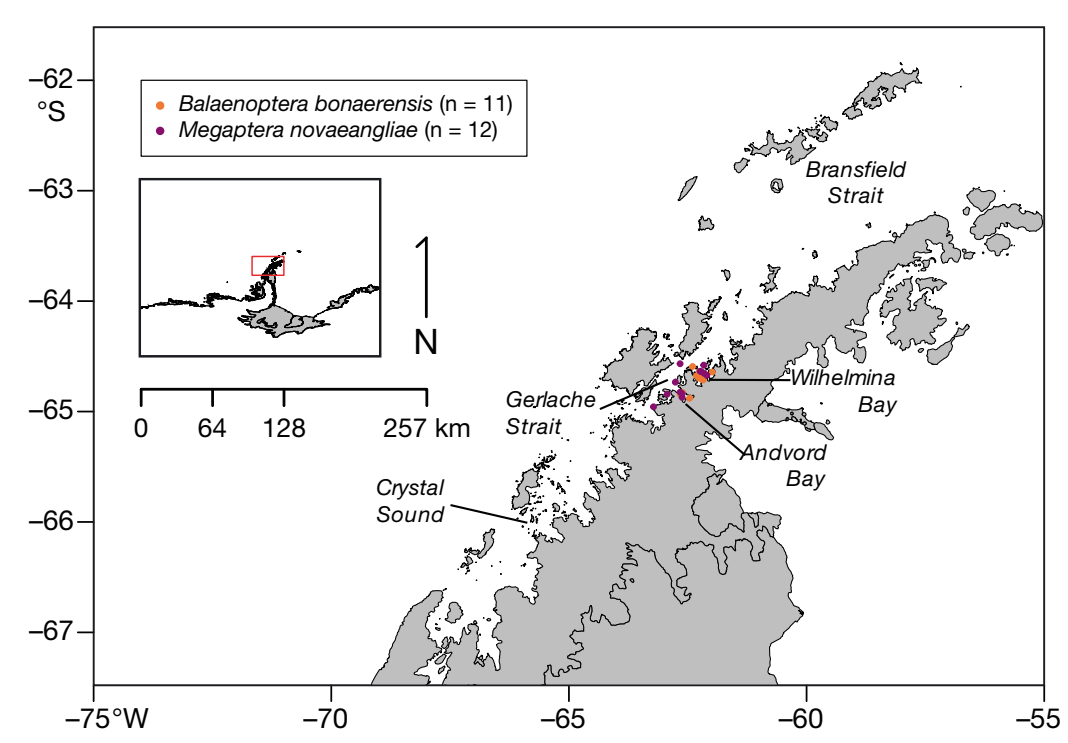

Fig. 1. Study area in the region surrounding the Gerlache and Bransfield Straits on the western side of the Antarctic peninsula. Deployment locations for tags on Antarctic minke whales and humpback whales are indicated by orange and purple circles, respectively 


\subsection{Tags}

We deployed 2 configurations of Argos-linked satellite tags during February 2013 in the vicinity of the Gerlache Strait on the western side of the Antarctic Peninsula. Most were custom-designed trans-dermal tags with an implantable housing containing a Wildlife Computers Spot 5 transmitter used in humpback whale tags or a SIRTRACK KiwiSat 202 (Cricket) platform-transmitting terminal (PTT) used in AMW tags. Implantable tag housings were built from surgical grade stainless steel and sterilized before each deployment (Gales et al. 2009). In addition, 3 of the tags deployed on AMWs were of the limited-impact minimally percutaneous (LIMPET) configuration, containing Spot 5 (PTT 126261) or Splash 10 (PTT $126262,126263)$ transmitters from Wildlife Computers. LIMPET tags were each attached by a pair of barbed titanium attachment darts that were sterilized before deployment (Andrews et al. 2008). Tags were programmed to activate after attachment with a conductivity switch and duty-cycled to transmit over 3 or $6 \mathrm{~h}$ intervals each day, up to $12 \mathrm{~h}$ of total transmission time per day for the implantable tags and $18 \mathrm{~h}$ for the LIMPET tags. The LIMPET tags were programmed to duty cycle to only transmit on every fifth day, following 20 continuous initial days. With these configurations, a single AA battery provided up to $270 \mathrm{~d}$ of active life for the implant tags, and lithium batteries provided up to $50 \mathrm{~d}$ for the LIMPET tags. More detailed telemetry methods were reported by Weinstein et al. (2017) for the implantable tags and Ainley et al. (2020) for the LIMPET tags. This work was permitted by the US Marine Mammal Protection Act by the National Marine Fisheries Service, The Antarctic Conservation Act by the National Science Foundation, The Australian Antarctic Division, and Duke University Institutional Animal Care and Use Committee.

\subsection{Habitat covariates}

We examined 8 habitat covariates that could potentially influence humpback and AMW resource selection decisions: depth, bathymetric slope, distance to the continental shelf, habitat enclosure, availability, sea ice concentration, distance to sea ice edge, and chlorophyll concentration. These covariates, along with response variables and availability surfaces described throughout this section, were all organized into a spatial grid at a resolution of $0.04^{\circ}(\sim 2 \mathrm{~km})$ using the 'raster' package (Hijmans 2020) in R (R Core Team 2020).
We obtained bathymetric data surrounding the Antarctic continent at a native resolution of $500 \mathrm{~m}$ in an Antarctic polar stereographic projection from the International Bathymetric Chart of the Southern Ocean (IBCSO) (Arndt et al. 2013; http://hs.pangaea .de/Maps/bathy/IBCSO_v1/IBCSO_v1_is_PS71_500m _tif.zip). Slope was calculated from the IBCSO bathymetric data using built-in functions of ArcGIS 11.0 (ESRI).

The continental shelf break demarcating the boundary between the continental shelf and the continental slope was defined at the $450 \mathrm{~m}$ depth contour. This contour corresponded to the approximate median depth at which the slope of the continental shelf surrounding the Antarctic Peninsula increased beyond $5 \%$. This contour also aligns closely with the coarser-resolution continental shelf margin defined in the seafloor geomorphic features map (Harris et al. 2013). The distance from the shelf break contour to each cell in the spatial grid was calculated as the minimum cumulative travel distance using the Path Distance tool in ArcGIS 11.0 (ESRI). This allowed the calculation of minimum travel distances that avoided obstacles for cetaceans (e.g. land). Distances to the shelf break contour with a bathymetric depth of $<450$ m (i.e. continental shelf habitats) were given a negative sign, while distances $\geq 450$ m (i.e. continental slope, open ocean basins, or shelf deeps) were given a positive sign.

An index denoting the degree to which marine habitats were enclosed by surrounding land was developed to differentiate the more enclosed bay and fjord habitats from those more exposed to the open ocean along the west Antarctic Peninsula. This continuous metric was calculated by taking a median of distance-to-land measurements in 36 directions. From each pixel in our spatial grid, we generated 36 lines in $10^{\circ}$ increments, and using the 'distGeo' function in the R package 'geosphere' (Hijmans 2019), we calculated distances to the nearest intersection with a coastline polygon layer (British Antarctic Survey Antarctic Digital Database, https://add.data.bas.ac. $\mathrm{uk} /$ ). In directions where no land was intersected in $>80 \mathrm{~km}$, the index value was capped at 1 .

We developed a seasonal sea ice index using a composite of cloud-free areas from $0.0044^{\circ}$ ( 250 m) resolution visible spectrum imagery from daily Aqua and Terra MODIS true color-corrected layers obtained from NASA WorldView (https://worldview. earthdata.nasa.gov/). Floating ice, whether glacial or marine derived, contrasted strongly with the surrounding open water, allowing it to be readily identified based on brightness. Within each cloud-free 
patch, brightness values ranging from 0 to 255 were truncated at 30, which empirically provided a strong differentiation between identifiable ice objects (e.g. bergs, sea ice) and surrounding open water, while minimizing the inclusion of confounding brightness signals such as phytoplankton blooms and suspended sediments. Clouds represented another potentially confounding brightness signal. Consequently, we identified and manually generated polygon shapefiles representing cloud-free areas in each daily true color image using ArcGIS 10.6.1. The Aqua and Terra MODIS Cloud Phase Optical Properties layer was used as an initial guide for cloud cover with secondary confirmation of cloud-free status based on close visual inspection. These cloud-free patches in daily rasters were compiled into a single overall seasonal composite layer using the 'calc' function in the $\mathrm{R}$ package 'raster' over the period when tags were transmitting in 2013 by calculating mean brightness values across all overlapping patches. Although seasonally averaged, this ice index provided much higher resolution than comparable microwave-wavelength sea ice concentration products (e.g. AMSR-2 and AMSR_E products with a peak resolution of $3.5 \mathrm{~km}$ ). Crucially, this MODIS imagery provided information on ice distribution within fjords and narrow channels that in many cases were unresolved in AMSR-2 and AMSR_E products because of relatively coarse land masks and complex topography. These fjords and channels represented important habitats for AMWs and humpback whales. Sea ice extent was defined by an index contour that was chosen to correspond approximately with the $15 \%$ sea ice concentration threshold used to define sea ice extent in microwavewavelength products. This contour was selected to roughly correspond with the threshold typically used to define sea ice extent, although our sea ice index based on relative brightness did not directly equate to sea ice concentration, having not undergone the same ground-truthing and validation. Distance to sea ice was then calculated as the path distance (see distance to shelf calculation above) to this sea ice index contour, with grid cell centroids falling within sea ice having a negative sign and distance measurements outside of sea ice having a positive sign.

Seasonal composite mean chlorophyll a ( $\mathrm{chl}$ a) concentration measurements $\left(\mathrm{mg} \mathrm{m}^{-3}\right)$ were obtained from Aqua and Terra MODIS level 3 products (https:// oceancolor.gsfc.nasa.gov/cgi/13) at a $0.042^{\circ}$ resolution for the austral summer (days of the year 355-366 and 1-60) of 2012-13. This product also had a relatively restrictive land mask that excluded most bays, channels, and nearshore habitats. To examine resource selection with respect to chlorophyll over the full range of marine habitats occupied by AMWs and humpback whales, we interpolated from the nearest available grid points to the unresolved nearshore grid points using an inverse distance weighting (Shepard 1968) algorithm implemented in ArgGIS 11.0. Fig. 1 shows the surfaces created for these habitat covariates around the Antarctic Peninsula.

\subsection{Continuous-time correlated random walk models}

Argos Doppler telemetry fixes were obtained from each tagged whale by processing transmissions using either classical Argos nonlinear least squares methods (e.g. location classes 3, 2, 1, 0, A, B) for the implant tags or a Kalman filtering algorithm for the LIMPET tags (Lopez \& Malardé 2011). State-space continuous-time correlated random walk (CTCRW) models (Johnson et al. 2008) fitted using the R package 'crawl' (version 2.1, Johnson et al. 2013) were used to derive an estimate of the unobserved true path of each individual. Posterior distributions were subsequently used to simulate multiple possible individual movement paths from CTCRW models, reflecting both observation uncertainty (i.e. location classes or error ellipses) and process uncertainty (i.e. true variation in the underlying movement process). A set of 100 simulated tracks from each fitted CTCRW model was imputed at regular 30 min intervals from irregularly spaced telemetry fixes. These simulated tracks were used to estimate utilization distributions (UDs) for each individual and were combined to estimate a joint UD for each species (Johnson et al. 2011). In addition, a subset of 10 simulated tracks was used to fit spatial point process (SPP) resource selection function (RSF) models described in Section 2.5, and these tracks were down-sampled from 30 min intervals to $2 \mathrm{~h}$ intervals because of the computational and memory constraints in the SPP analysis. Because 'crawl' CTCRW models were unaware of obstacles constraining the cetacean movements, simulated paths that crossed land were re-routed to avoid unavailable habitats using a least-cost path distance function implemented in the 'fix_path' function in 'crawl.' UDs were estimated using the approach described by Johnson et al. (2011), which involved counting the number of imputed locations from 100 simulated tracks per individual that fell within each raster grid cell. UD contours were calculated such that 50 and $90 \%$ of the estimated probability density (i.e. simulated points) fell within the respective polygons. 


\subsection{SPP models}

RSF models employing an SPP framework were implemented to assess the environmental covariates associated with preferential habitat use in AMWs and humpback whales. Our modeling approach was based on space-time point process models for animal telemetry data developed by Johnson et al. (2013), marginalized over the time dimension to yield an SPP model (Johnson et al. 2013, Hooten et al. 2017). We modeled counts of simulated locations $\left(\lambda_{l}\right)$ as an approximately Poisson process (Equation 4.51 in Hooten et al. 2017):

$$
\log \left(\lambda_{l}\right)=x^{\prime}\left(\mu_{1}\right) \beta+\eta_{1}\left(\mu_{1}, \theta_{1}\right)+\eta_{2}\left(\hat{u}\left(\mu_{l}\right), \theta_{2}\right)
$$

with an 'availability' surface $\left(\eta_{1}, \eta_{2}\right)$ and habitat covariates $(x)$ as explanatory variables. In this model, the availability component consisted of a spatial random effect term modeled as a 2D thin-plate regression spline of easting and northing $\left(\eta_{1}\right)$, and a 1D thin-plate regression spline describing a 'redistribution kernel' $\left(\eta_{2}\right.$; Moorcroft \& Barnett 2008). The redistribution kernel accounted for the sequential dependence between telemetry fixes, using a kernel intensity surface to represent the approximate probability of displacements of different lengths away from the animal's simulated position at the time step $t-1$. A kernel intensity surface for each time step was estimated based on Equation 4.49 of Hooten et al. (2017), with parameters of (1) maximum sustained travel speeds (defined a priori at $15 \mathrm{~km} \mathrm{~h}^{-1}$ for both species based on the speed measurements of Ford et al. 2005 and Noad \& Cato 2007); (2) the durations of the time step between $t$ and $t-1$; and (3) the distances from the animals' positions at time step $t-1$ to each other point in the spatial grid. These individual kernel intensity surfaces, which in shape approximately resemble a bivariate normal distribution (Johnson et al. 2013), were summed across each time step in each individual's track to derive an overall redistribution kernel surface for each simulated track $(n=10)$. However, because this surface approximates the underlying UD with some additional smoothing, this surface was therefore collinear with effects of the habitat covariates that were the target of inference in our RSF model. To account for habitat availability without masking the resource selection effects, we fitted a linear regression model between the kernel intensity values and habitat covariates and then took the residuals from this model to derive an orthogonal redistribution kernel surface.

An approximately Poisson distributed response variable for each simulated track $(n=10)$ was calcu- lated by counting simulated animal locations within cells of the same grid used to store the covariates and redistribution kernel surfaces. Note that simulations from CTCRW models diverged in a highly erratic manner during extended periods when PTT tags were not transmitting due to duty cycling (i.e. 1-5 d). Because simulated tracks during duty cycle periods contained little to no biologically meaningful information on habitat use, we excluded them from the calculation of the response variables and the estimation of redistribution kernel surfaces periods when the tag was duty cycled off for $\geq 1 \mathrm{~d}$.

The response vector and design matrix used in fitting the model were developed by concatenating counts of simulated locations, redistribution kernels, and covariates across the 10 simulated tracks. We then arrived back at the appropriate sample size by down-weighting the influence of each row (representing grid cell $i$ in simulated track $j$ ) by a value of $1 / 10$. We defined the spatial support in which we conducted our modeling as the area with a redistribution kernel intensity $>0.01$, which represented $\sim 1 /$ 10000 of the maximum kernel intensity values. We also limited our study area to the west Antarctic Peninsula region between the northern tip of the Antarctic Peninsula and Marguerite Bay to the south. This region encompassed the vast majority of AMW and humpback whale telemetry fixes and differed substantially from the adjacent Weddell and Bellingshausen Seas, being predominately free of sea ice during the period of our tracking effort.

Instead of estimating parametric coefficients ( $\beta$ ) as in Hooten et al. (2017), we estimated low-order (i.e. effective degrees of freedom, EDF < 4) thin-plate regression spline smooth functions associated with the habitat covariates using the 'bam' function in the R package 'mgcv' (version 1.8; Wood 2006). The 'bam' function is an analogue of the more widely used generalized additive model function 'gam' that has been optimized for large datasets. In this model we also jointly estimated the 1D and 2D thin-plate regression spline smooth functions associated with the availability surface components $\left(\eta_{1}, \eta_{2}\right)$ described above. All of these terms were specified as shrinkage spline penalties, which allowed the EDF associated with individual terms to be shrunk to essentially zero, effectively eliminating those terms from the model. This allowed 'mgcv' to implement an integrated model selection process within the generalized cross-validation model fitting algorithm, instead of undertaking a secondary model selection process based on, for example, Akaike's information criterion. 
A surface representing the selection component of the model (i.e. excluding the availability surface and the intercept) was estimated by summing the predicted smooth function responses associated with each covariate. More detailed information and scripts for all modeling work can be found in the Supplement at www.int-res.com/articles/suppl/m669p001_supp.pdf.

\section{RESULTS}

\subsection{Movement behavior}

We deployed PTTs on 12 humpback whales and 11 AMWs between 2 and 12 February 2013 (Table 1). Tracks from the humpback whales ranged from 4.6 to $181.8 \mathrm{~d}$ in length, with an average of $52.2 \pm 14.5 \mathrm{~d}$ (SE; Table 1). Tracks from the AMWs were shorter in duration and ranged from 1.7 to $53.4 \mathrm{~d}$, with an aver-

Table 1. Instrument deployment information from the tracking of Antarctic minke whale Balaenoptera bonaerensis ( $\mathrm{n}=$ 11) and humpback whale Megaptera novaeangliae ( $\mathrm{n}=12)$ individuals using Argos platform transmitting terminal (PTT) tags (Wildlife Computers). Tags were deployed on B. bonaerensis and $M$. novaeangliae individuals along the west Antarctic Peninsula during the austral summer of 2012/2013. Pre-migration transmission duration and number of location fixes represent totals over the period from tag deployment to either tag loss/failure or departure from the foraging grounds

\begin{tabular}{lccc} 
PTT & $\begin{array}{c}\text { Deployment date } \\
(\mathrm{mo} / \mathrm{d} / \mathrm{yr}) \text { and time }(\mathrm{h})\end{array}$ & $\begin{array}{c}\text { Transmission } \\
\text { duration }(\mathrm{d})\end{array}$ & $\begin{array}{c}\text { Argos } \\
\text { fixes }(\mathrm{n})\end{array}$ \\
\hline $\begin{array}{l}\text { Antarctic } \\
\text { minke whales }\end{array}$ & & \\
126271 & $2 / 2 / 1313: 19$ & 5.8 & 361 \\
126263 & $2 / 6 / 1315: 26$ & 49.3 & 1032 \\
126262 & $2 / 11 / 1317: 59$ & 29.2 & 600 \\
112733 & $2 / 8 / 1312: 38$ & 1.7 & 47 \\
112734 & $2 / 8 / 1314: 45$ & 13.7 & 369 \\
112736 & $2 / 9 / 1312: 20$ & 35.7 & 889 \\
112731 & $2 / 9 / 1312: 24$ & 13.9 & 304 \\
112747 & $2 / 9 / 1312: 27$ & 6.3 & 1744 \\
112745 & $2 / 9 / 1312: 32$ & 7.3 & 2539 \\
112750 & $2 / 9 / 1315: 21$ & 53.4 & 2834 \\
112748 & $2 / 9 / 1316: 01$ & 16.1 & 249 \\
Humpback & whales & & \\
112737 & $2 / 6 / 1318: 48$ & 68.7 & 2019 \\
112738 & $2 / 6 / 1318: 44$ & 63.8 & 1729 \\
112746 & $2 / 7 / 1318: 31$ & 61 & 1964 \\
121207 & $2 / 12 / 1317: 42$ & 40.6 & 2521 \\
121208 & $2 / 5 / 1323: 25$ & 21.3 & 164 \\
121210 & $2 / 5 / 1318: 58$ & 102 & 2649 \\
121211 & $2 / 6 / 1323: 55$ & 37.5 & 1058 \\
121212 & $2 / 6 / 1317: 01$ & 4.6 & 146 \\
123224 & $2 / 5 / 1323: 30$ & 32 & 2349 \\
123231 & $2 / 5 / 1323: 26$ & 8.3 & 118 \\
123232 & $2 / 6 / 1317: 03$ & 181.8 & 2277 \\
123236 & $2 / 5 / 1317: 16$ & 4.8 & 1394 \\
& & & \\
\hline
\end{tabular}

age of $21.1 \pm 5.4 \mathrm{~d}$ (Table 1 ). The mean number of locations received per day was comparable between humpbacks and AMWs (Table 1). Overall, humpback whales ranged over a broader area and a broader range of habitats than AMWs (Fig. 2). AMWs spent a large portion of their time in nearshore waters around the west Antarctic Peninsula (Fig. 2a,c), but also ranged considerably farther to the south and west into the Bellingshausen Sea and to the north and east into the Scotia and Weddell Seas (e.g. Lee et al. 2017). However, this was not reflected in the UDs because of the high density use of substantially fewer areas. In contrast, humpback whales concentrated their distribution and movement during the feeding season over the continental shelf around the west Antarctic Peninsula, from the northern tip of the west Antarctic Peninsula south to Marguerite Bay (Fig. 2b) while also regularly occupying coastal bays. This resulted in a UD that includes the Bransfield Strait and waters surrounding the South Shetland Islands. While this region showed high humpback whale use and little AMW presence, the coastal waters and bays stretching from the southern portion of the Gerlache Strait to the Crystal Sound area north and east of Adelaide Island experienced high use by AMWs but little by humpback whales.

\subsection{Habitat covariates}

Along with the remote sensing products used directly as predictors of AMW and humpback whale habitat use (e.g. bathymetric depth, chl a), Fig. 3 presents 2 environmental covariates synthesized specifically for this modeling effort: (1) an index of enclosure by land and (2) a sea ice index. In the enclosure index surface (Fig. 3e), grid cells falling within bays and narrow channels yielded high enclosure index values reflecting the close proximity of land along a majority of 36 compass bearings. In contrast, waters surrounding prominent coastline features, such as exposed capes and coastlines that were open to the Southern Ocean or the Bransfield Straight in many directions, yielded enclosure index values closer to 0 .

The sea ice index surface (Fig. 3c) represents a composite of brightness values from cloud-free areas in 32 Aqua MODIS satellite visible spectrum images over the period 12 January to 27 March 2013. In $83 \%$ sea ice index grid cells where there were $\geq 2$ cloudfree days, the median grid cell coefficient of variation was $12.8 \%$. We empirically selected the 0.15 sea ice index contour (Fig. 3c) to define sea ice extent in the calculation of the distance to sea ice surface (Fig. 3d). 
a)

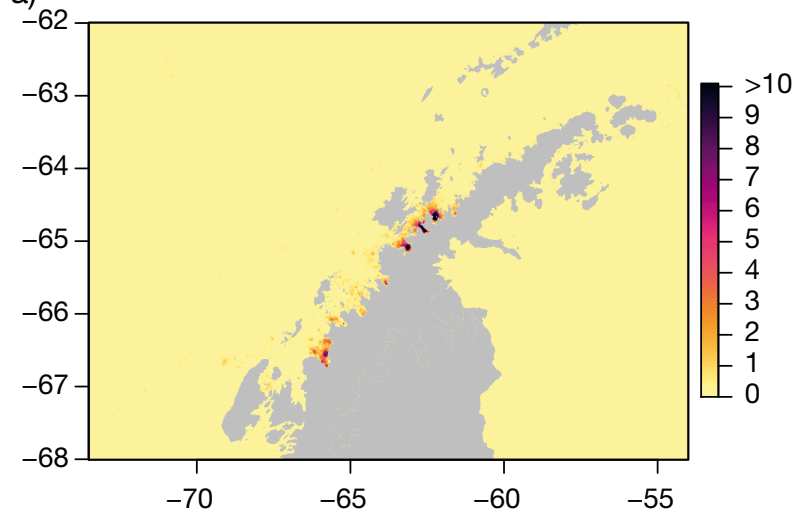

c)

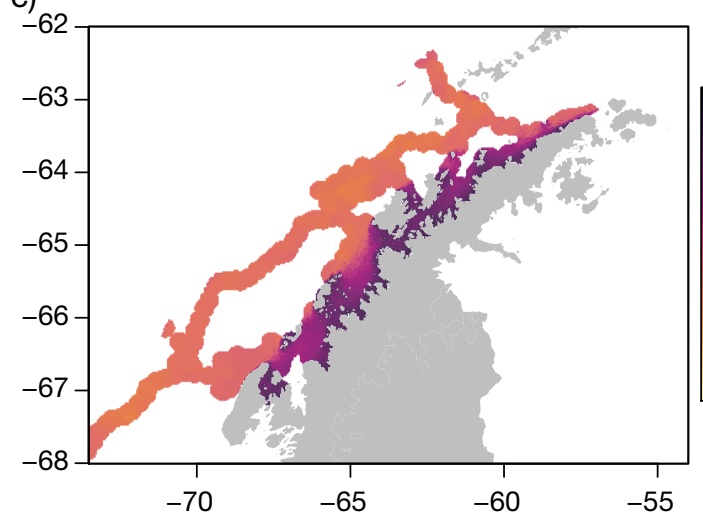

b)

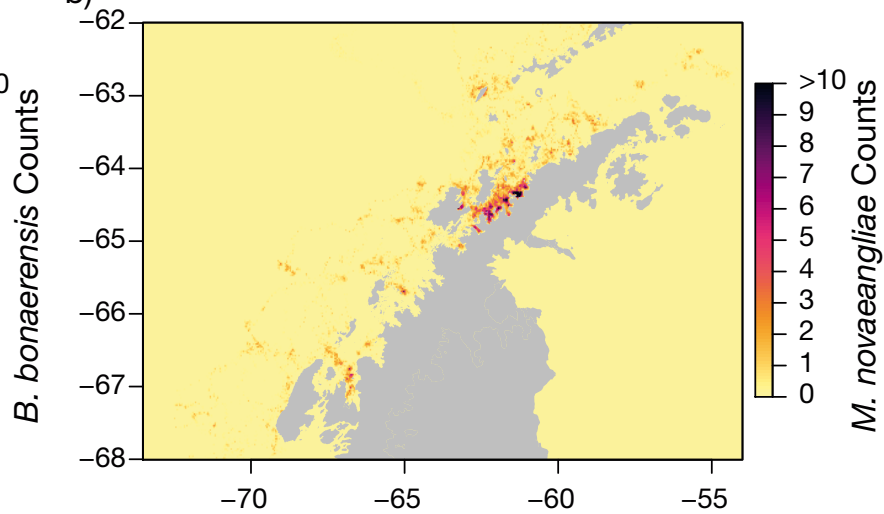

d)

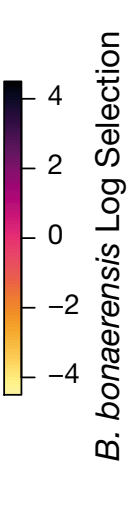

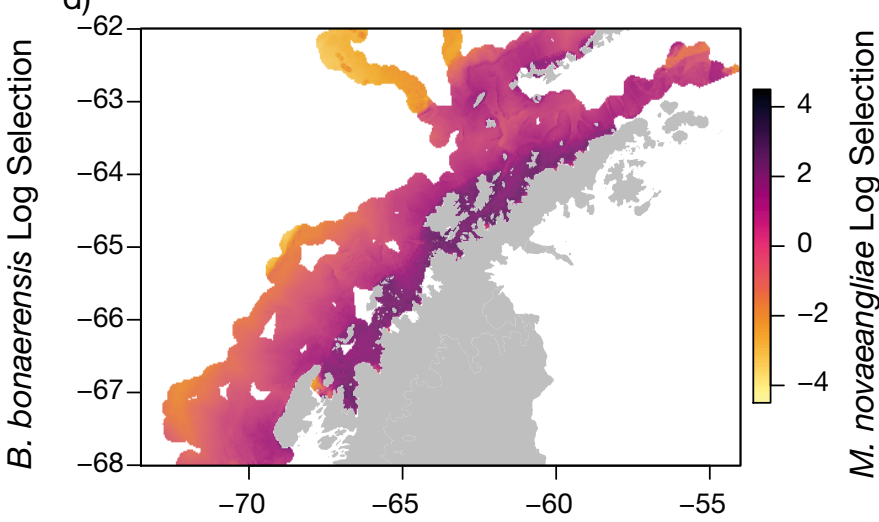

Fig. 2. $(\mathrm{a}, \mathrm{b})$ Counts of simulated locations derived from $\mathrm{n}=10$ imputations of continuous time correlated random walk models fitted to Argos location fixes from Antarctic minke whales (Balaenoptera bonaerensis; $\mathrm{n}=11$ ) and humpback whales (Megaptera novaeangliae; $\mathrm{n}=12$ ). These represent the response variables used in fitting spatial point process (SPP) models. (c,d) Log selection surfaces predicted from SPP models. These surfaces represent the combined effects of the environmental covariate smooth functions, after accounting for habitat availability given spatially and temporally auto-correlated Argos telemetry fixes and spatial random effects

\subsection{SPP models}

The SPP model fitted using Argos telemetry fixes from the tagged AMW individuals overall explained $77.5 \%$ of the deviance in the counts of imputed locations. Several RSF smooth terms contributed significant effects to the overall AMW SPP model fit (Table 2), after controlling for habitat availability between successive location estimates using a smooth function of the orthogonal redistribution kernel surface and a bivariate spatial random effect smooth function to absorb residual spatial autocorrelation. Looking at the combined effect of these RSF smooth terms (Fig. 4), AMWs showed primarily disproportionate positive selection for marine habitats that were more enclosed (i.e. closely surrounded by land; Fig. 4a) relative to the overall prevalence of these habitats within the spatial support of the SPP model. There were also smaller but still substantive selection effects against elevated chlorophyll concentrations (Fig. 4b) and for habitats in closer proximity to sea ice (Fig. 4c). The distance to sea ice term partially covaried with the enclosure index, showing a correlation coefficient of 0.56 . This reflected the co-occurrence of high ice concentrations with more enclosed habitats near the heads of fjordic bays, where ice was continually being input into the marine environment by tide water glaciers and where winds and currents that erode and disperse ice were in many cases reduced by surrounding land (Fig. 4d). This intercorrelation, which resulted in a pairwise observed concurvity between enclosure and distance to sea ice of 0.51 , was insufficient to exclude this term from the model on the basis of multi-collinearity; however, this interplay of variables made it difficult to infer which variable was most important in AMW habitat selection.

The overall humpback whale SPP model explained $61.0 \%$ of the deviance in the counts of bihourly imputed locations from the Argos tracks of the tagged individuals. In this model, all of the resource selection covariate terms returned significant effects (Table 3), although significance in this case may to some extent have reflected sample size, and some of 
a)

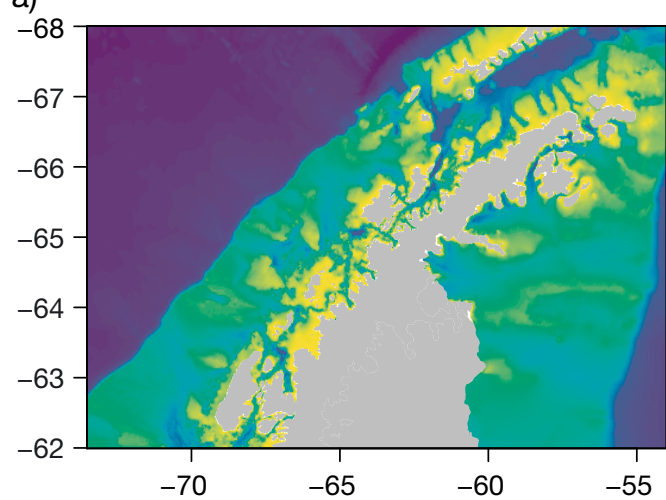

c)

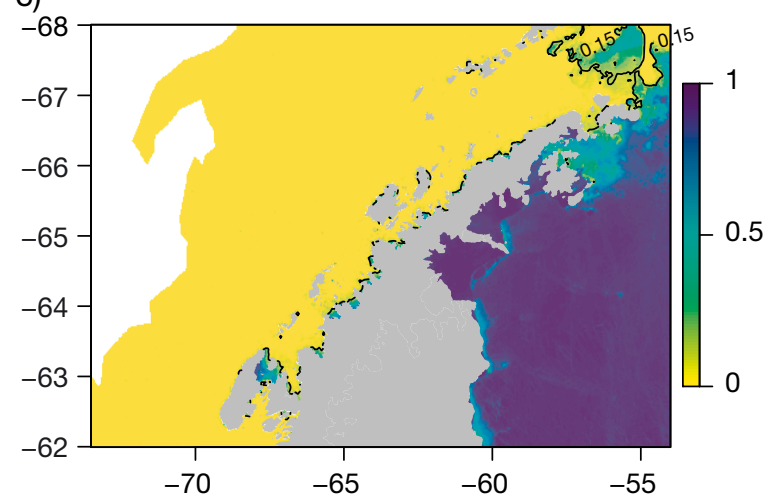

e)

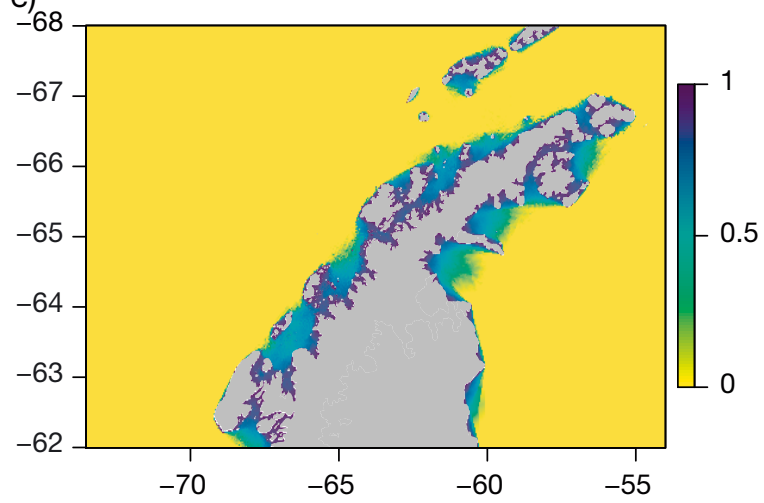

b)
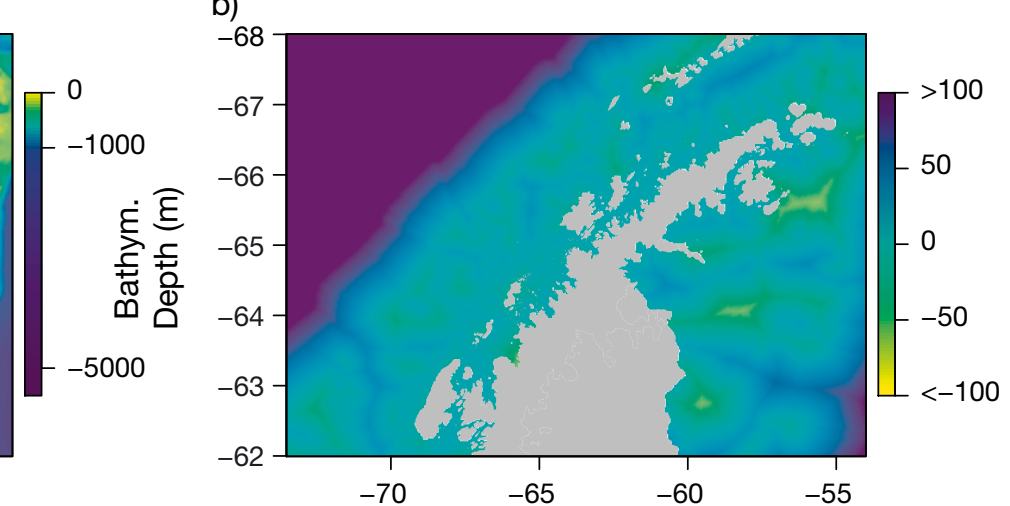

d)
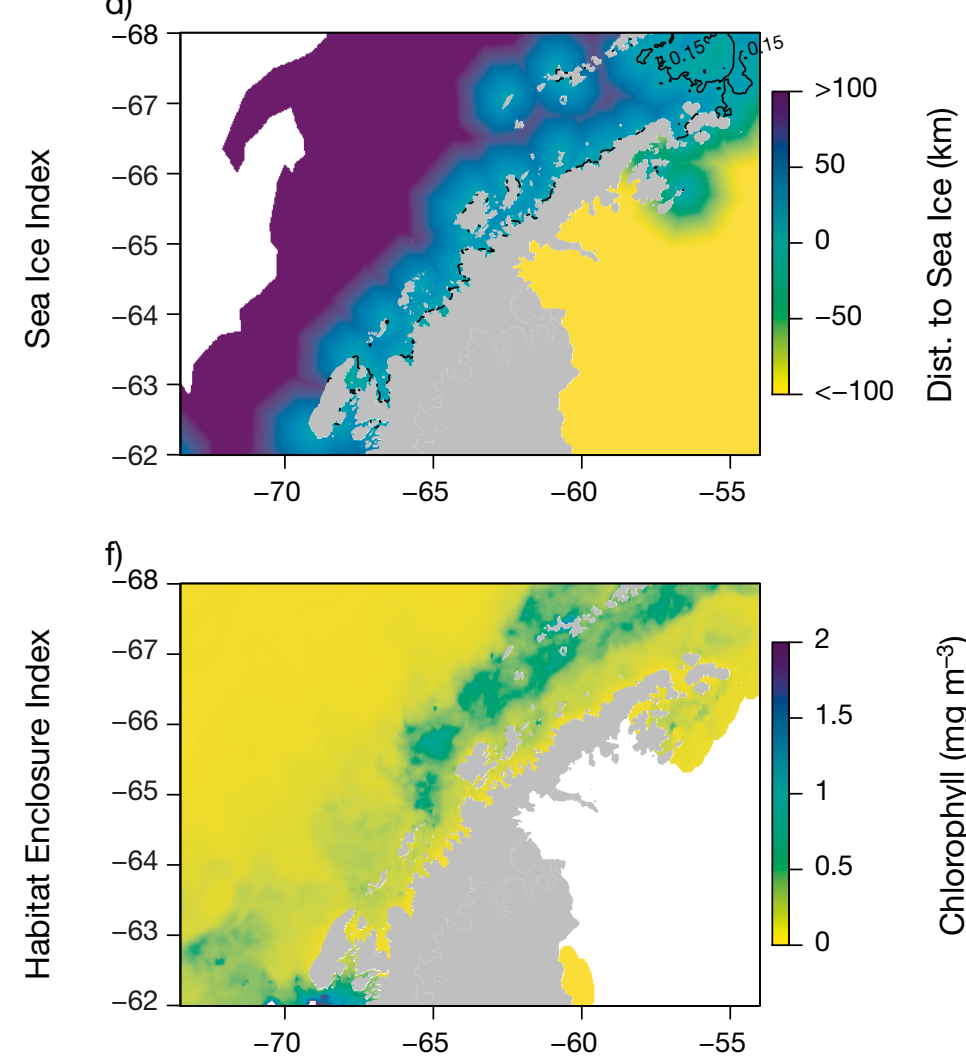

Fig. 3. Habitat covariates considered as potential influences on Antarctic minke whale B. bonaerensis and humpback whale $M$. novaeangliae resource selection including: (a) bathymetric depth, (b) distance to the continental shelf break (450 $\mathrm{m}$ isobath), (c) sea ice index (compiled from cloud-free MODIS TrueColor imagery, 2013), (d) distance to 0.15 sea ice index contour, (e) habitat enclosure index (median distance to land), and (f) chlorophyll concentration (MODIS seasonal composite; 21 December 2012 - 20 March 2013)

these effect sizes are relatively small. After accounting for habitat availability and spatial random effect components of the SPP model, humpback whales showed a more diffuse pattern of log selection (Fig. 5) than AMWs, in part reflecting the more diffuse pattern of habitat utilization (Fig. 3d). Notably, humpback whales showed comparatively strong selection for habitats proximate to sea ice (Fig. 5a) and more enclosed habitats (Fig. 5f). However, this species also showed relatively strong selection against elevated sea ice areas (Fig. 5b). This can be seen in the overall humpback whale log resource selection surface, which shows negative log selection in the back of some bays where elevated ice concentrations persisted during austral summer (i.e. lingering fast ice and/or glacial inputs). This contrasts with the ice index for AMWs (Table 2), which showed generally neutral selection up to ice index values of 
Table 2. Parameter estimates and goodness of fit metrics describing the effects of the availability, spatial random effect, and resource selection components of space-only space-time point process (STPP) models for Antarctic minke whale Balaenoptera bonaerensis. STPP models were fitted to counts of simulated locations drawn from 10 imputations of continuous time correlated random walk models that were developed on the basis of Argos location fixes from $n=11$ individuals. EDF: effective degrees of freedom

\begin{tabular}{|llcccc|}
\hline Smooth_Terms & Model_Component & EDF & Ref.df & $\chi^{2}$ & $\mathrm{p}$ \\
\hline s(Dist. to Shelf) & Resource selection & 0.4 & 4 & 0.7 & 0.1389 \\
s(Bathymetric Depth) & Resource selection & 0.9 & 4 & 5.6 & 0.0061 \\
s(Enclosure Index) & Resource selection & 2.7 & 4 & 369 & $<0.001$ \\
s(Slope) & Resource selection & 0.4 & 4 & 0.6 & 0.1964 \\
s(Sea Ice Index) & Resource selection & 2.3 & 4 & 9 & 0.0059 \\
s(Dist. to Sea Ice) & Resource selection & 0.6 & 4 & 1.7 & 0.0525 \\
s([Chl-a]) & Resource selection & 0.9 & 4 & 6.5 & 0.0027 \\
s(Orthogonal Kernel & Availability & 5.5 & 9 & 2173 & $<0.001$ \\
$\quad$ Availability) & & & & & \\
s(Easting, Northing) & Spatial random effect & 15.7 & 29 & 79.3 & $<0.001$ \\
\hline
\end{tabular}

approximately 0.7 , above which there was a modest negative selection effect. Humpback whales also exhibited positive selection for shallower habitats

a)

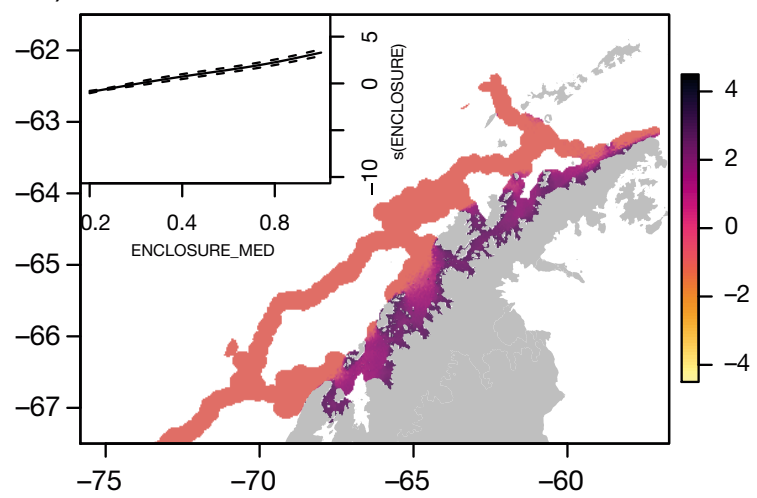

c)

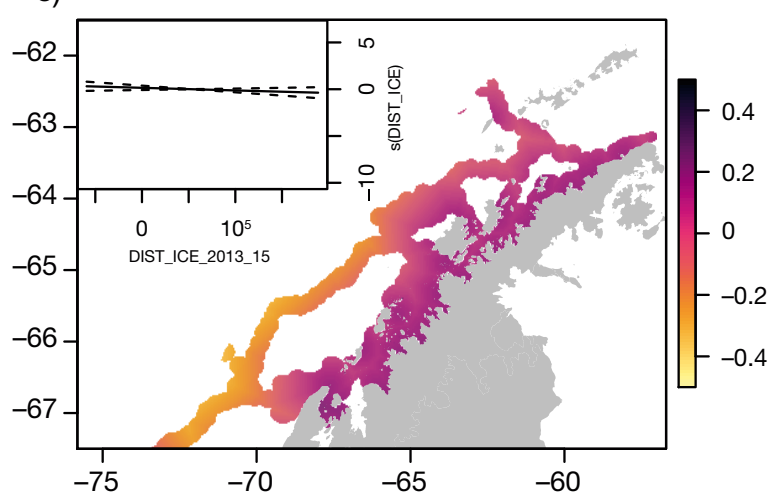

(Fig. 5d) and for steeper bathymetric slopes (Fig. 5e).

\subsection{UDs}

Taking into account the uncertainty in true animal locations inherent in intermittent Argos-quality telemetry fixes, there was considerable overlap in the overall ranges of AMWs and humpback whales (Fig. 3c,d), with both species encompassing a wide span of habitats along the continental margin of the west Antarctic Peninsula. However, the observed UDs of AMWs ( $\mathrm{n}=$ 11) and humpback whales $(\mathrm{n}=12)$ shown in Fig. 6a,b also illustrate subtle, yet appreciable, differences in the emphasis of habitat use by each species. There was only $37 \%$ overlap of the AMWs $50 \%$ UD contour with the comparable UD contour from humpback

b)

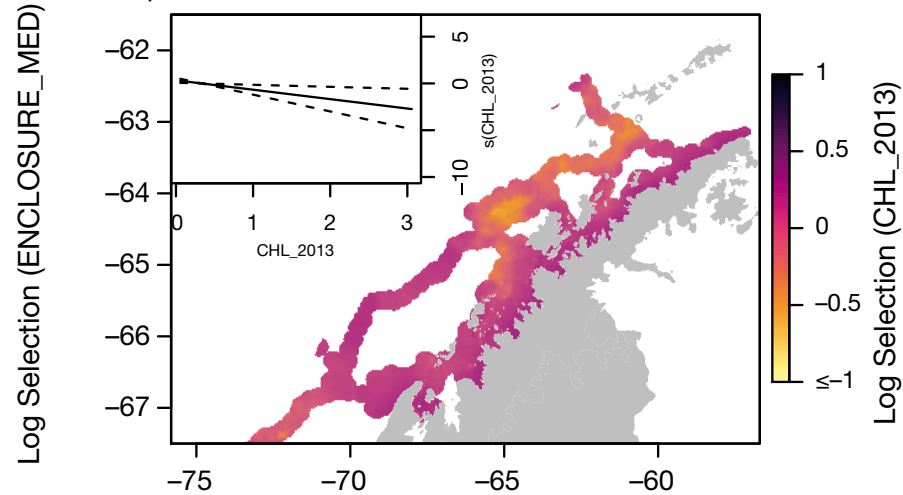

d)

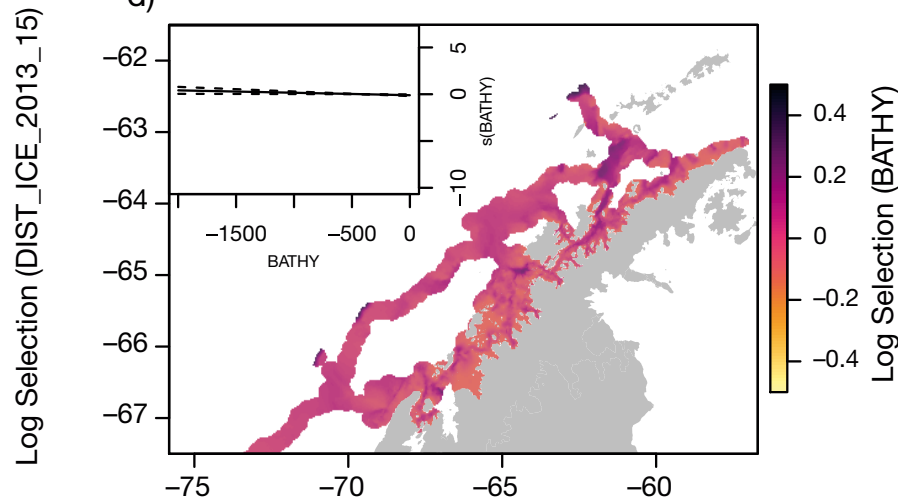

Fig. 4. Smooth functions with standard error estimates (insets) and predicted effects of specific covariates contributing to the log selection surface (see Fig. 2c) from a spatial point process (SPP) model derived from the tracks of 11 Antarctic minke whales B. bonaerensis in austral summer and fall of 2013: (a) enclosure index, (b) chlorophyll concentration, (c) distance to 0.15 sea ice index contour, (d) bathymetry. Note the negative selections against more exposed habitats, as well as negative selection against higher chlorophyll and habitats more distant from sea ice 
Table 3. Parameter estimates and goodness of fit metrics describing the effects of the availability, spatial random effect, and parametric habitat covariate components of space-only space-time point process (STPP) models for humpback whale Megaptera novaeangliae. STPP models were fitted to counts of simulated locations drawn from 10 imputations of continuous time correlated random walk (CTCRW) models that were developed on the basis of Argos location fixes from $n=12$ individuals. EDF: effective degrees of freedom

\begin{tabular}{|llcccc|}
\hline Smooth_Terms & Model_Component & EDF & Ref.df & $\chi^{2}$ & $\mathrm{p}$ \\
\hline s(Dist. to Shelf) & Resource selection & 1.1 & 4 & 33 & $<0.001$ \\
s(Bathymetric Depth) & Resource selection & 1.6 & 4 & 146.4 & $<0.001$ \\
s(Enclosure Index) & Resource selection & 1.6 & 4 & 269.6 & $<0.001$ \\
s(Slope) & Resource selection & 1.2 & 4 & 223.7 & $<0.001$ \\
s(Sea Ice Index) & Resource selection & 1.8 & 4 & 529.8 & $<0.001$ \\
s(Dist. to Sea Ice) & Resource selection & 1.7 & 4 & 277.9 & $<0.001$ \\
s([Chl-a]) & Resource selection & 0.9 & 4 & 15.7 & $<0.001$ \\
s(Orthogonal Kernel & $\quad$ Availability & 5.3 & 9 & 6300.4 & $<0.001$ \\
Availability) & & & & & \\
s(Easting, Northing) & Spatial random effect & 21.9 & 29 & 172.7 & $<0.001$ \\
\hline
\end{tabular}

whales (Fig. 6d). Likewise, there was only $39 \%$ overlap of the $90 \%$ UD contours (Fig. 6c). AMWs and humpback whales both showed concentrated activity in the Gerlache Strait with substantial habitat use overlap, particularly in Wilhelmina and Andvord Bays. The emphasis of both species on the Gerlache Strait area in part reflected limited dispersal from initial tagging locations during the transmission lives of certain tags, with tagging mainly occurring within the comparatively protected waters of Wilhelmina and Andvord Bays (Fig. 6a,b). However, among the subset of AMWs that did disperse beyond the Gerlache Straight area (8 of 11), habitat utilization hotspots also generally occurred within more enclosed bay habitats to the northeast and southwest along the west Antarctic Peninsula coast. Humpback whales also showed areas of intense habitat utilization along the Gerlache Strait, including in some of the bays. However, habitat utilization by humpback whales appears to have been concentrated closer to the entrances of bays as well as to a greater extent within the open straights compared with AMWs. Overall, the humpback whale individuals tagged in this study utilized a broader range of habitats than tagged AMW individuals, although they remained primarily over the continental shelf and shelf deep geomorphological features (Fig. 6b).

\section{DISCUSSION}

Our tag-derived animal-movement analysis provides a means for determining species-habitat associations that are based on long-term behavior of indi- viduals rather than individual points across a surveyed area. We found that humpback whales ranged over broad areas of the continental shelf, associated with environmental features that aggregate their prey (Antarctic krill), and used core areas that include entrances of nearshore embayments. In contrast, AMW movement was focused in coastal areas, and their core habitat included coastal embayments where ice (either remnant sea ice or glacial brash) occurred. Despite species-specific differences in habitat association patterns, humpback and minke whales exhibited high sympatry in their core habitat use.

The data used in the present study provide a mechanism to evaluate how predators with similar prey types and habitats partition resources to maintain sympatry and reduce the potential for competition during primary feeding times. Similar to the conceptual framework of habitat partitioning developed in terrestrial systems (Hutchinson 1959), we found consistencies in the drivers that affect distribution patterns and overlap among closely related marine predators. Larger humpback whales moved broadly in relation to ephemeral high-density prey patches (e.g. Weinstein et al. 2017), whereas AMWs maintained smaller core areas that likely minimize predation risk yet provide enough prey to meet their energetic needs. The methods developed to determine these association patterns have broad application for other marine animals that are tractable to biologging studies, and allow for a more robust means to further compare and contrast ecological interactions between marine and terrestrial ecosystems.

Together with differences in body size and energetic demands, our results suggest that humpback whales can forage over larger areas in order to satisfy their relatively greater metabolic needs, whereas prey are abundant enough for AMWs to remain almost exclusively in coastal bays and nearshore areas during summer months. AMWs have predictably very low feeding costs, estimated to be similar to the cost of slow and steady swimming (Potvin et al. 2012), and thus exhibit high lunge frequencies for a given breath-hold dive (Friedlaender et al. 2014). Moreover, the size of the engulfment apparatus relative to the body in AMWs is comparatively small (i.e. low mass-specific engulfment capacity), and as a result, filtration time after a lunge-feeding event is short (Kahane-Rapport et al. 2020). Therefore, lunge- 
a)

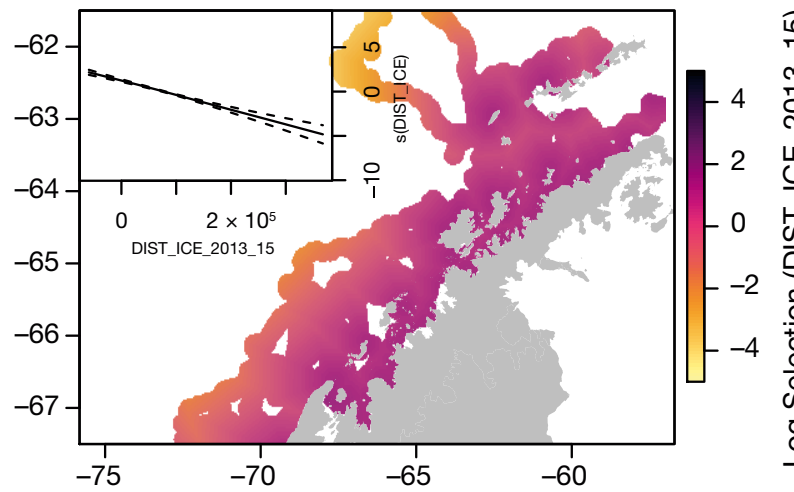

c)

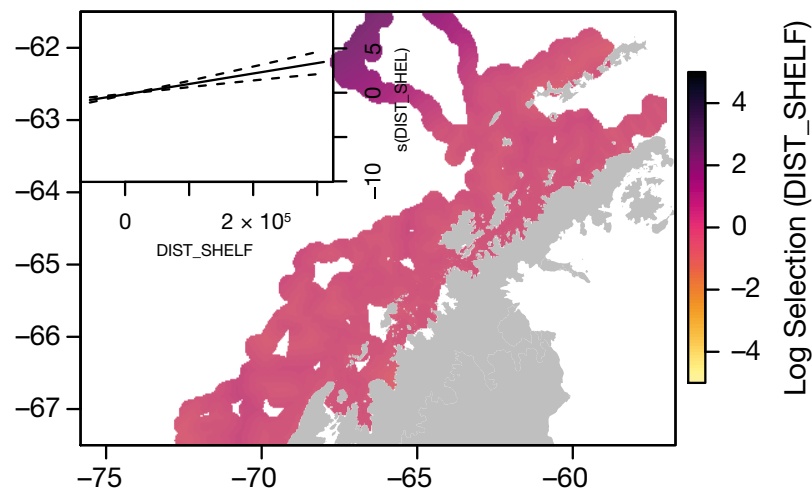

e)

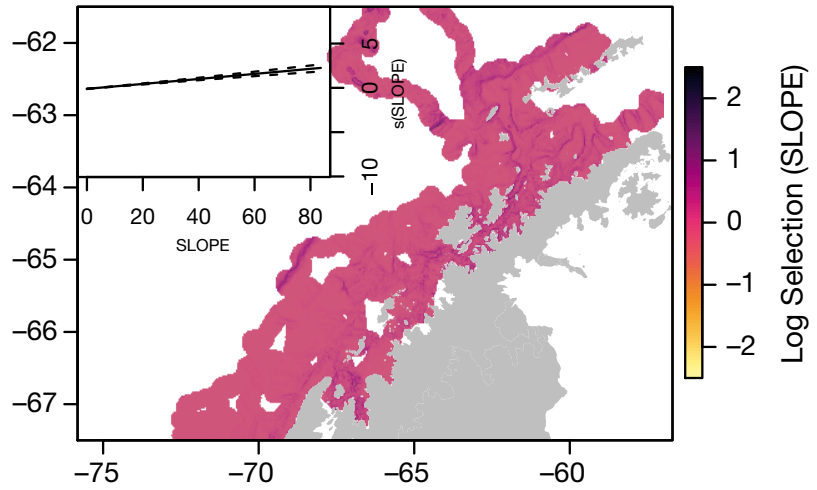

b)

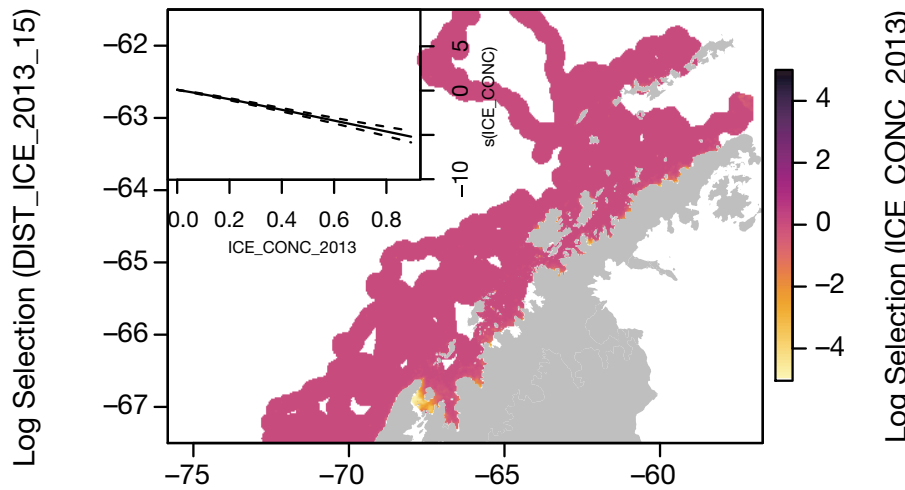

d)

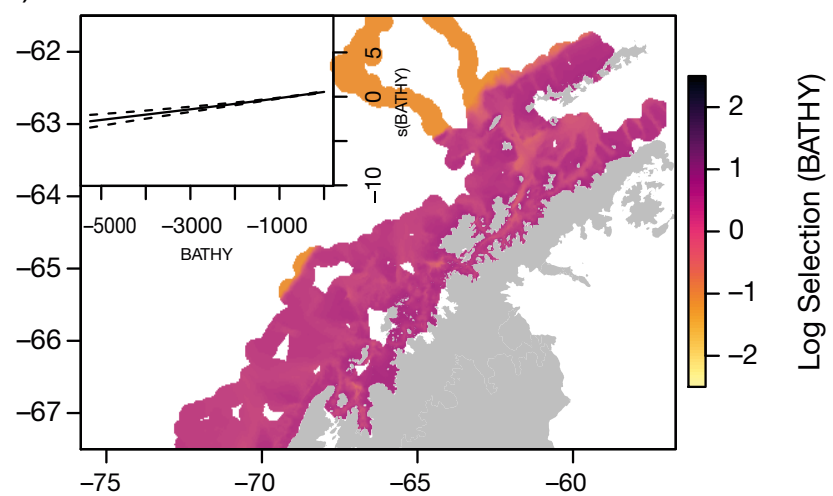

f)

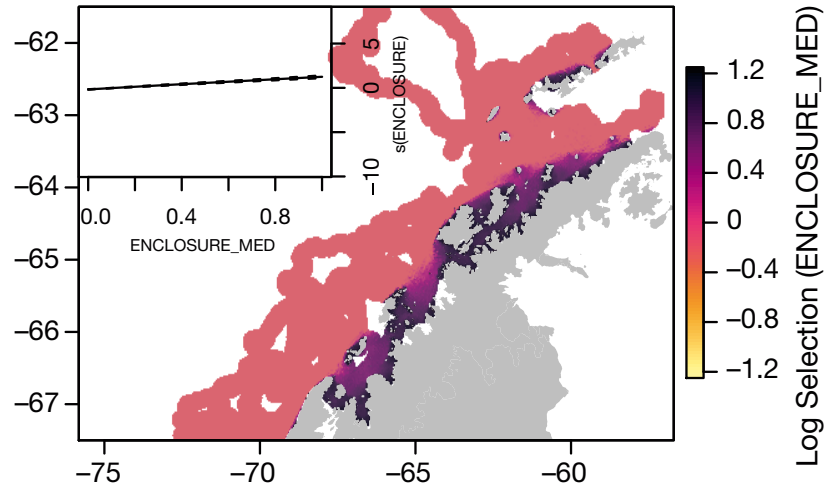

Fig. 5. Smooth functions with standard error estimates (insets) and predicted effects of specific covariates contributing to the log selection surface (see Fig. 2d) from a spatial point process (SPP) model derived from the tracks of 12 humpback whales M. novaeangliae in austral summer and fall of 2013: (a) distance to 0.15 sea ice index contour, (b) ice concentration, (c) distance to shelf, (d) bathymetry, (e) slope, (f) enclosure index. Humpback whales show positive selection for more enclosed habitats and proximity to sea ice, but there was also relatively strong negative selection for elevated sea ice index values (i.e. selection for habitat in close proximity to, but not within areas of dense sea ice/brash). In addition, we see positive selection for shallower habitats particularly near steep bathymetric slopes

feeding rates per unit time are also very high in AMWs, and this may facilitate the exploitation of more patchily distributed krill such as those located under and around sea ice (Friedlaender et al. 2014). The small overall body size of AMWs allows for enhanced maneuverability in these complex and dynamic sea ice-filled environments. In contrast, humpback whales have lower overall lunge feeding rates (e.g. Ware et al. 2011, Goldbogen et al. 2019), contributing to their need to target higher densities of prey to be able to satisfy increased energetic demands relative to AMWs.

During summer months, krill are broadly distributed across coastal and continental shelf waters, and 
a)

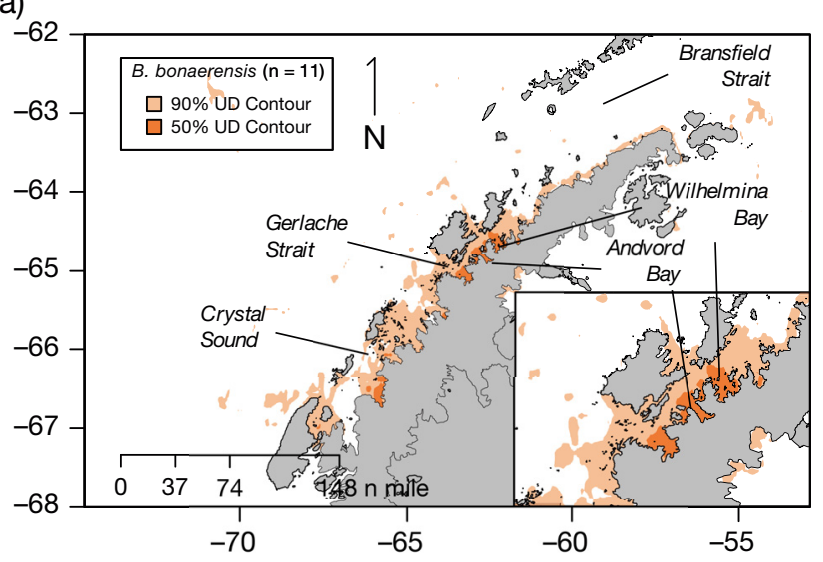

c)

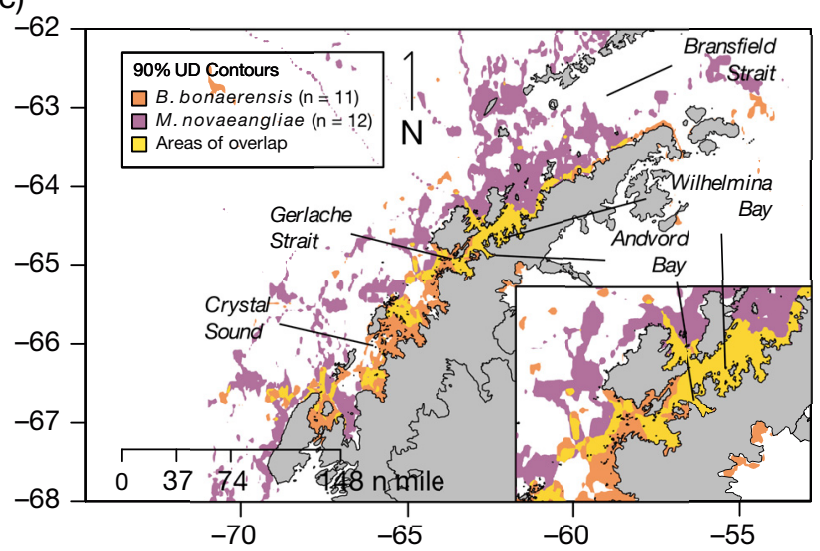

b)

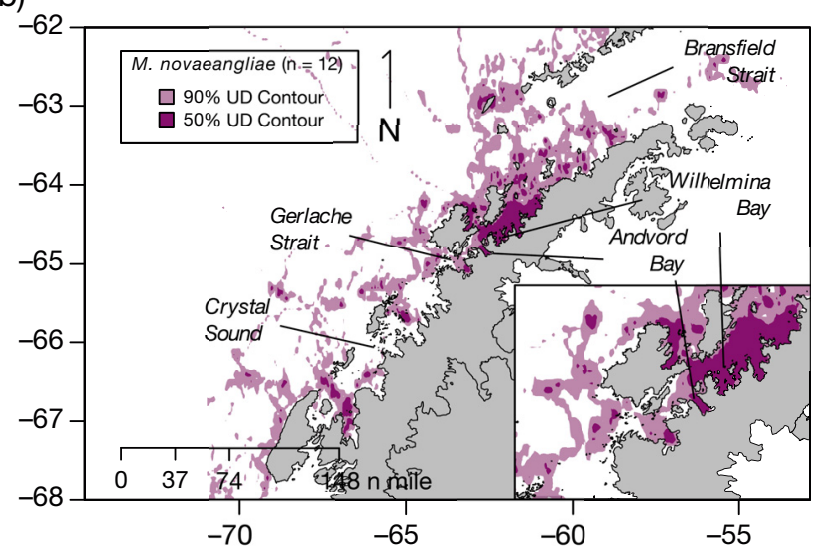

d)

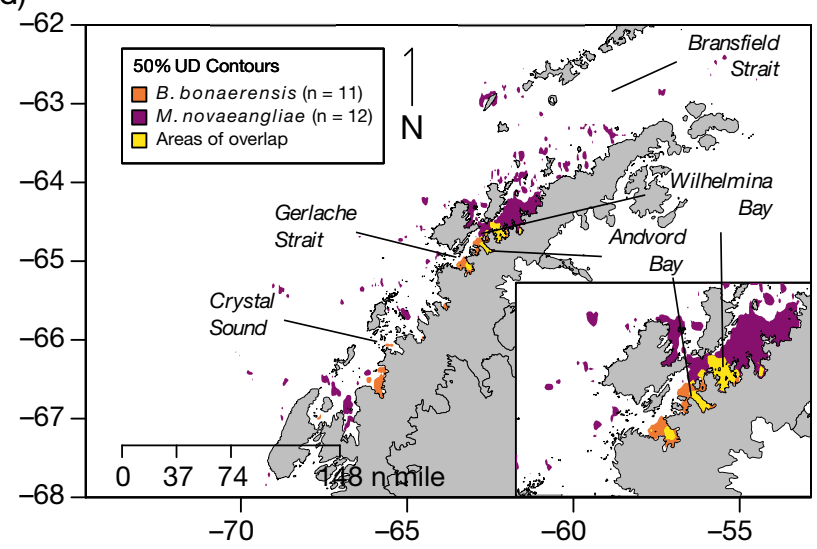

Fig. 6. Observed 50 and $90 \%$ habitat utilization distribution (UD) contours from (a) Antarctic minke whales (B. bonaerensis; $\mathrm{n}=11$ ) and $(\mathrm{b})$ humpback whales $(M$. novaeangliae; $\mathrm{n}=12)$ tracked off the west Antarctic Peninsula during the austral summer and fall of 2013. Also shown are areas of (c) $90 \%$ and (d) $50 \%$ UD contour overlap. UD estimates derive from $\mathrm{n}=100 \mathrm{im}-$ putations drawn from continuous time correlated random walk models fitted using Argos location fixes. First transmission locations of each satellite transmitter in February 2013 are shown for each species, with tagging activity concentrated in protected bays (e.g. Wilhelmina, Andvord) along the Gerlache Strait

females deposit eggs in deeper water (Nicol 2006). That humpback whales have been shown to forage over expansive areas during summer (Curtice et al. 2015, Weinstein et al. 2017) speaks to their need to actively seek and associate with their prey. The nearshore bays associated with the Gerlache and Bransfield Straits are known to be critical foraging areas for other krill predators around the Antarctic Peninsula during both summer and fall (Henley et al. 2019). During summer, a guild of central place foragers (animals that forage over a limited area and carry resources back to a fixed point) numbering in the millions, including penguins, seabirds, and pinnipeds, utilizes this region exclusively to provision growing offspring. Combined with previous work on krill foraging hotspots (Hindell et al. 2020), our results further confirm that the Antarctic Peninsula is of critical ecological importance and must be prioritized in conservation planning during summer months.
Humpback whale decision making is largely focused on foraging, whereas AMWs must balance foraging with the risks associated with predation (e.g. Brown et al. 1999, Laundré et al. 2010). Predation by killer whales is thought to occur primarily in open water (Fearnbach et al. 2019), where AMWs are chased to the point of exhaustion (Ford et al. 2005). Nearshore bays act to consolidate sea ice and brash ice produced from calving glaciers, creating more suitable habitat for AMWs to avoid predation. Thus, while these areas are occupied by humpback whales and may contain high densities of prey, AMWs may choose a trade-off between having enough prey in a smaller area with lower predation risk than searching for higher-quality prey in a more dangerous open-water environment. Future studies that track the movements of killer whales, AMWs, and the simultaneous instances of krill foraging and whale predation will inform how these factors have shaped the evolution of krill predator behavior in the Southern Ocean. 
This information on the habitat associations between species may become more important in light of rapid ecosystem changes currently occurring around the Antarctic Peninsula. These changes include increasing air temperatures and a concurrent decrease in the extent and duration of the annual sea ice (e.g. Vaughan et al. 2003, Stammerjohn et al. 2008, Meredith et al. 2017), which likely diminishes preferred habitat for ice obligate species. Conditions in this region are now allowing for more temperate flora and fauna to encroach into areas with more ice-adapted species assemblages (crabs, flowering plants, etc.) (e.g. Avila et al. 2020). Among krill predators, ice-obligate Adélie penguin Pygoscelis adeliae populations have diminished and breeding colonies are sequentially moving south (e.g. Cimino et al. 2016) concurrent with increases in gentoo penguin $P$. papua colonies (a sub-Antarctic species) from the north (Levy et al. 2016). Previous work with AMWs demonstrates that this species eventually vacates areas without sea ice and moves to regions where it is more prevalent (Lee et al. 2017). Given the environmental changes occurring and the needs of these species, our results likely represent and already reflect a decaying habitat that will result in regime shifts in the structure and foundation of these ecosystems.

Our study provides insights into ecological relationships between sympatric krill-dependent predators with different habitat preferences that will likely be inversely impacted by current and rapid environmental change similar to what has recently been modeled for other krill consumers in this environment (Hückstädt et al. 2020). Previous work using satellite-derived home ranges of closely related and sympatric krill predators has found differences in the amount of spatial overlap during feeding among penguins at fine spatial scales (e.g. Pickett et al. 2018). However, the data used in the present study provide a novel mechanism to evaluate how predators with similar prey types and habitats partition resources to maintain sympatry during primary feeding times and over larger spatial scales. As conditions on the western side of the Antarctic Peninsula change from a polar to a sub-polar environment, it is possible that humpback whales will benefit in the short term by an increase in open-water areas and time while preferred sea ice habitat for AMWs will diminish. Continued monitoring of the behavior, demographic patterns, pregnancy rates, distribution, and abundance of each of these species may elucidate the consequences of climate-related physical and biological changes occurring in this ecosystem and similar to those being seen in other polar regions (Hamilton et al. 2019).
Acknowledgements. We thank the Captain and crew of the RV 'Point Sur' for their support and efforts in helping to collect these data. We also thank Bob Pitman, Matt Bowers, and Reny Tyson for their contributions to data collection in the field. For their support of the project, we are grateful to Diana Nemergut, Alex Isern, and Tim McGovern of the National Science Foundation, and to Caroline Casey for her helpful comments on the manuscript. We are also grateful to colleagues at the Australian Antarctic Division, including Mike Double, Virginia Andrews Goff, and Elanor Bell, for their support of this research as part of the Southern Ocean Research Partnership. Research was conducted under ACA Permit 2009-013, NMFS Permit 14907, and Duke University IACUC protocol A49-12-02. This research was supported by a National Science Foundation Office of Polar Programs RAPID award 1250208 and by the Lindblad ExpeditionsNational Geographic Fund.

\section{LITERATURE CITED}

Acevedo-Gutiérrez A, Croll DA, Tershy BR (2002) High feeding costs limit dive time in the largest whales. J Exp Biol 205:1747-1753

Ainley DG, Joyce TW, Saenz B, Pitman RL and others (2020) Foraging patterns of Antarctic minke whales in McMurdo Sound, Ross Sea. Antarct Sci 32:454-465

Andrews RD, Pitman RL, Balance LT (2008) Satellite tracking reveals distinct movement patterns for Type B and Type C killer whales in the southern Ross Sea, Antarctica. Polar Biol 31:1461-1468

Arndt JE, Schenke HW, Jakobsson M, Nitsche FO and others (2013) The International Bathymetric Chart of the Southern Ocean (IBCSO) Version 1.0-A new bathymetric compilation covering circum-Antarctic waters. Geophys Res Lett 40:3111-3117

Arsenault R, Owen-Smith N (2008) Resource partitioning by grass height among grazing ungulates does not follow body size relation. Oikos 117:1711-1717

Atkinson A, Hill SL, Pakhomov EA, Siegel V and others (2019) Krill (Euphausia superba) distribution contracts southward during rapid regional warming. Nat Clim Change 9:142-147

Avila C, Angulo-Preckler C, Martín-Martín RP, Figuerola B, Griffiths HJ, Waller CL (2020) Invasive marine species discovered on non-native kelp rafts in the warmest Antarctic island. Sci Rep 10:1639

Bejder M, Johnston DW, Smith J, Friedlaender A, Bejder L (2016) Embracing conservation success of recovering humpback whale populations: evaluating the case for downlisting their conservation status in Australia. Mar Policy 66:137-141

Bianucci G, Marx FG, Collareta A, Di Stefano A, Landini W, Morigi C, Varola A (2019) Rise of the titans: Baleen whales became giants earlier than thought. Biol Lett 15:20190175

* Bombosch A, Zitterbart DP, Van Opzeeland I, Frickenhaus S, Burkhardt E, Wisz MS, Boebel O (2014) Predictive habitat modelling of humpback (Megaptera novaeangliae) and Antarctic minke (Balaenoptera bonaerensis) whales in the Southern Ocean as a planning tool for seismic surveys. Deep-Sea Res I 91:101-114

Brown JS, Laundré JW, Gurung M (1999) The ecology of fear: optimal foraging, game theory, and trophic interactions. J Mammal 80:385-399

Cimino MA, Moline MA, Fraser WR, Patterson-Fraser DL, Oliver MJ (2016) Climate-driven sympatry may not lead 
to foraging competition between congeneric toppredators. Sci Rep 6:18820

Clapham PJ, Brownell RL (1996) The potential for interspecific competition in baleen whales. Rep Int Whaling Comm 46:361-370

Curtice C, Johnston DW, Ducklow H, Gales N, Halpin PN, Friedlaender AS (2015) Modeling the spatial and temporal dynamics of foraging movements of humpback whales (Megaptera novaeangliae) in the Western Antarctic Peninsula. Mov Ecol 3:13

Dixon AFG (2007) Body size and resource partitioning in ladybirds. Popul Ecol 49:45-50

Fearnbach H, Durban JW, Ellifrit DK, Pitman RL (2019) Abundance of Type A killer whales (Orcinus orca) in the coastal waters off the western Antarctic Peninsula. Polar Biol 42:1477-1488

Ford JK, Ellis GM, Matkin DR, Balcomb KC, Briggs D, Morten AB (2005) Killer whale attacks on minke whales: prey capture and antipredator tactics. Mar Mamm Sci 21: 603-618

Friedlaender AS, Halpin PN, Qian SS, Lawson GL, Wiebe PH, Thiele D, Read AJ (2006) Whale distribution in relation to prey abundance and oceanographic processes in shelf waters of the Western Antarctic Peninsula. Mar Ecol Prog Ser 317:297-310

Friedlaender AS, Lawson GL, Halpin PN (2009) Evidence of resource partitioning between humpback and minke whales around the western Antarctic Peninsula. Mar Mamm Sci 25:402-415

Friedlaender AS, Johnston DW, Fraser WR, Burns J, Costa DP (2011) Ecological niche modeling of sympatric krill predators around Marguerite Bay, Western Antarctic Peninsula. Deep-Sea Res II 58:1729-1740

Friedlaender AS, Goldbogen JA, Nowacek DP, Read AJ, Johnston D, Gales N (2014) Feeding rates and under-ice foraging strategies of the smallest lunge filter feeder, the Antarctic minke whale (Balaenoptera bonaerensis). J Exp Biol 217:2851-2854

Gales N, Double MC, Robinson S, Jenner C and others (2009) Satellite tracking of southbound East Australian humpback whales (Megaptera novaeangliae): challenging the feast or famine model for migrating whales. Rep SC/61/ SH17. International Whaling Commission, Cambridge

Goldbogen JA, Calambokidis J, Croll DA, McKenna MF and others (2012) Scaling of lunge-feeding performance in rorqual whales: mass-specific energy expenditure increases with body size and progressively limits diving capacity. Funct Ecol 26:216-226

Goldbogen JA, Cade DE, Calambokidis J, Friedlaender AS, Potvin J, Segre PS, Werth AJ (2017) How baleen whales feed: the biomechanics of engulfment and filtration. Annu Rev Mar Sci 9:367-386

Goldbogen JA, Cade DE, Wisniewska DM, Potvin J and others (2019) Why whales are big but not bigger: physiological drivers and ecological limits in the age of ocean giants. Science 366:1367-1372

"Hamilton CD, Vacquié-Garcia J, Kovacs KM, Ims RA, Kohler J, Lydersen C (2019) Contrasting changes in space use induced by climate change in two Arctic marine mammal species. Biol Lett 15:20180834

Harris PT, Macmillan-Lawler M, Rupp J, Baker E (2013) Global seafloor geomorphic features map: applications for ocean conservation and management. American Geophysical Union, Fall Meeting 2013. Abstract ID: OS23D-1679
Henley SF, Schofield OM, Hendry KR, Schloss IR and others (2019) Variability and change in the west Antarctic Peninsula marine system: research priorities and opportunities. Prog Oceanogr 173:208-237

*Herr H, Viquerat S, Siegel V, Kock KH and others (2016) Horizontal niche partitioning of humpback and fin whales around the West Antarctic Peninsula: evidence from a concurrent whale and krill survey. Polar Biol 39:799-818

*Hijmans RJ (2019) geosphere: spherical trigonometry. R package version 1.5-10. https:/CRAN.R-project.org/ package $=$ geosphere

*Hijmans RJ (2020) raster: geographic data analysis and modeling. $\mathrm{R}$ package version 3.4-5. https://CRAN.R-project.org/package $=$ raster

*Hindell MA, Reisinger RR, Ropert-Coudert Y, Hückstädt LA and others (2020) Tracking of marine predators to protect Southern Ocean ecosystems. Nature 580:87-92

Hooten MB, Johnson DS, McClintock BT, Morales JM (2017) Animal movement: statistical models for telemetry data. CRC Press, Boca Raton, FL

Hückstädt LA, Piñones A, Palacios DM, McDonald BI and others (2020) Projected shifts in the foraging habitat of crabeater seals along the Antarctic Peninsula. Nat Clim Change 10:472-477

* Hutchinson GE (1959) Homage to Santa Rosalia or why are there so many kinds of animals? Am Nat 93:145-159

* Johnson DS, London JM, Lea MA, Durban JW (2008) Continuous-time correlated random walk model for animal telemetry data. Ecology 89:1208-1215

Johnson DS, London JM, Kuhn CE (2011) Bayesian inference for animal space use and other movement metrics. J Agric Biol Environ Stat 16:357-370

Johnson DS, Hooten MB, Kuhn CE (2013) Estimating animal resource selection from telemetry data using point process models. J Anim Ecol 82:1155-1164

Kahane-Rapport SR, Goldbogen JA (2018) Allometric scaling of morphology and engulfment capacity in rorqual whales. J Morphol 279:1256-1268

Kahane-Rapport SR, Savoca MS, Cade DE, Segre PS and others (2020) Lunge filter feeding biomechanics constrain rorqual foraging ecology across scale. J Exp Biol 223:jeb224196

*Laundré JW, Hernández L, Ripple WJ (2010) The landscape of fear: ecological implications of being afraid. Open Ecol J 3:1-7

ㄴLee JF, Friedlaender AS, Oliver MJ, DeLiberty TL (2017) Behavior of satellite-tracked Antarctic minke whales (Balaenoptera bonaerensis) in relation to environmental factors around the western Antarctic Peninsula. Anim Biotelem 5:23

* Levy H, Clucas GV, Rogers AD, Leaché $\mathrm{AD}$ and others (2016) Population structure and phylogeography of the gentoo penguin (Pygoscelis papua) across the Scotia Arc. Ecol Evol 6:1834-1853

Lopez R, Malardé JP (2011) Improving ARGOS Doppler location using Kalman filtering. CLS-DT-MEMO-11-65. CLS, Ramonville Saint-Agne

*Menge BA, Chan F, Nielsen KJ, Lorenzo ED, Lubchenco J (2009) Climatic variation alters supply-side ecology: impact of climate patterns on phytoplankton and mussel recruitment. Ecol Monogr 79:379-395

Meredith MP, Stammerjohn SE, Venables HJ, Ducklow HW and others (2017) Changing distributions of sea ice melt and meteoric water west of the Antarctic Peninsula. Deep-Sea Res II 139:40-57 
Milne A (1961) Definition of competition among animals. In: Milthorpe FL (ed) Mechanisms in biological competition. Symp Soc Exp Biol 15. Cambridge University Press, Cambridge, p 40-61

Moorcroft PR, Barnett A (2008) Mechanistic home range models and resource selection analysis: a reconciliation and unification. Ecology 89:1112-1119

Murase H, Matsuoka K, Ichii T, Nishiwaki S (2002) Relationship between the distribution of euphausiids and baleen whales in the Antarctic $\left(35^{\circ} \mathrm{E}-145^{\circ} \mathrm{W}\right)$. Polar Biol 25: 135-145

Nicol S (2006) Krill, currents, and sea ice: Euphausia superba and its changing environment. BioScience 56:111-120

Noad MJ, Cato DH (2007) Swimming speeds of singing and non-singing humpback whales during migration. Mar Mamm Sci 23:481-495

Perrin WF, Mallette SD, Brownell RL Jr (2018) Minke whales: Balaenoptera acutorostrata and B. bonaerensis. In: Würsig B, Thewissen JGM, Kovacs KM (eds) Encyclopedia of marine mammals, $3^{\text {rd }}$ edn. Academic Press, Cambridge, MA, p 608-613

Pickett EP, Fraser WR, Patterson-Fraser DL, Cimino MA, Torres LG, Friedlaender AS (2018) Spatial niche partitioning may promote coexistence of Pygoscelis penguins as climate-induced sympatry occurs. Ecol Evol 8:9764-9778

Potvin J, Goldbogen JA, Shadwick RE (2012) Metabolic expenditures of lunge feeding rorquals across scale: implications for the evolution of filter feeding and the limits to maximum body size. PLOS ONE 7:e44854

R Core Team (2020) R: a language and environment for statistical computing. R Foundation for Statistical Computing, Vienna

Rasmussen K, Palacios DM, Calambokidis J, Saborío MT and others (2007) Southern Hemisphere humpback whales wintering off Central America: insights from water temperature into the longest mammalian migration. Biol Lett 3:302-305

Santora JA, Schroeder ID, Loeb VJ (2014) Spatial assess-

Editorial responsibility: Peter Corkeron,

Woods Hole, Massachusetts, USA

Reviewed by: 3 anonymous referees ment of fin whale hotspots and their association with krill within an important Antarctic feeding and fishing ground. Mar Biol 161:2293-2305

Schoener TW (1974) Resource partitioning in ecological communities. Science 185:27-39

Shepard D (1968) A two-dimensional interpolation function for irregularly-spaced data. Proceedings of the $196823^{\text {rd }}$ ACM National Conference, Association for Computing Machinery, New York, NY, p 517-524

Slater GJ, Goldbogen JA, Pyenson ND (2017) Independent evolution of baleen whale gigantism linked to PlioPleistocene ocean dynamics. Proc R Soc B 284:20170546

Stammerjohn SE, Martinson DG, Smith RC, Iannuzzi RA (2008) Sea ice in the western Antarctic Peninsula region: spatio-temporal variability from ecological and climate change perspectives. Deep-Sea Res II 55: 2041-2058

Stammerjohn S, Massom R, Rind D, Martinson D (2012) Regions of rapid sea ice change: an inter-hemispheric seasonal comparison. Geophys Res Lett 39:L06501

Trathan PN, Hill SL (2016) The importance of krill predation in the Southern Ocean. In: Siegel V (ed) Biology and ecology of Antarctic krill. Springer, Cham, p 321-350

*Vaughan DG, Marshall GJ, Connolley WM, Parkinson C and others (2003) Recent rapid regional climate warming on the Antarctic Peninsula. Clim Change 60:243-274

* Ware C, Friedlaender AS, Nowacek DP (2011) Shallow and deep lunge feeding of humpback whales in fjords of the West Antarctic Peninsula. Mar Mamm Sci 27:587-605

* Weinstein BG, Double M, Gales N, Johnston DW, Friedlaender AS (2017) Identifying overlap between humpback whale foraging grounds and the Antarctic krill fishery. Biol Conserv 210:184-191

*Williams R, Kelly N, Boebel O, Friedlaender AS and others (2014) Counting whales in a challenging, changing environment. Sci Rep 4:4170

Wood S (2006) Generalized additive models: an introduction with R. CRC Press, Boca Raton, FL

Submitted: November 10, 2020

Accepted: May 25, 2021

Proofs received from author(s): July 3, 2021 